\title{
Changing the Hidden Curriculum of Campus Rape Prevention and Education: Women's Self- Defense as a Key Protective Factor for a Public Health Model of Prevention
}

\author{
ABSTRACT \\ Recent activist, policy, and government efforts to engage in campus rape prevention education \\ (RPE), culminating in the 2014 White House Task Force recommendations to combat campus \\ sexual assault, prompt a need to examine the concept of "prevention" in the context of sexual \\ assault on U.S. college campuses and their surrounding community service agencies. This paper \\ reviews previous research on effective resistance to sexual assault, showing that self-defense is a \\ well-established protective factor in a public health model of sexual assault prevention. The \\ article goes on to show, through an examination of campus rape prevention efforts framed as \\ "primary prevention," that self-defense is routinely excluded. This creates a hidden curriculum \\ that preserves a gender status quo even while it strives for change. The article concludes with \\ recommendations for how administrators, educators, facilitators, funding agencies, and others \\ can incorporate self-defense into campus RPE for a more effective, data-driven set of sexual \\ assault prevention efforts.
}




\section{Changing the Hidden Curriculum of Campus Rape Prevention and Education: Women's Self-Defense as a Key Protective Factor for a Public Health Model of Prevention \\ A Crucial Juncture for College Campuses}

The prevalence of sexual assault against college women in the U.S. is well documented. Studies have reported repeatedly that at least one in five women will be sexually assaulted while at college (Fisher, Cullen, \& Turner, 2000; Tjaden \& Thoennes, 2006); a report released by the Center for Disease Control and Prevention (CDC) in September 2014 confirms these numbers (Breiding et al., 2014). But now college campuses find themselves at a crucial juncture, where national attention, student activism, resources, and demands for legal compliance are being directed at the problem of sexual assault on campus. Yet the relevant advocates, administrators, and agencies routinely ignore or dismiss the scholarship establishing the efficacy of women's self-defense for thwarting such attacks and transforming community norms that fuel sexual assault on campus.

From the 2011 "Dear Colleague" Letter (U.S. Department of Education, 2011) to the Campus Sexual Violence Elimination (SaVE) Act to the 2014 White House Task Force on Sexual Assault on College Campuses, universities have increased efforts to respond to the problem. Universities have sought to improve victim services and data collection about the incidence and prevalence of sexual assault. They have offered definitions of sexual assault and consent, clarifications of campus policy and law, and other forms of awareness. As of fall 2014, U.S. colleges and universities that receive federal funds are required to give sexual assault prevention education to all incoming students and staff. These campuses now have a government-imposed mandate to improve their reporting procedures, to protect the rights of those victimized by and accused of sexual assault, and to engage in sexual assault prevention 
(C)2015 Martha McCaughey \& Jill Cermele

Forthcoming in Trauma, Violence, \& Abuse

education (Campus Sexual Violence Elimination Act, 2014). ${ }^{1}$ While student activists have long demanded change to a campus rape culture (see, e.g., Gold \& Villari, 2000), and campuses have long engaged in what they consider rape prevention education (RPE), the problem of sexual assault has never been so high on university administrators' priority lists.

However, as this article will show, women's self-defense- knowing the data on it, training in it, or being told to use it - gets excluded from almost every articulation of sexual assault prevention by well-intentioned advocates, administrators, facilitators, educators, clinicians, and policy makers. The government's imposition of a mandate to emphasize prevention and/or prevention education prompts the need for our critical reflection on what has counted, and what will count, as "prevention" in rape prevention education.

The White House Task Force Report, "Not Alone," (2014a) refers readers to the Center for Disease Control and Prevention (CDC)'s public health model for sexual assault prevention (examined later in this paper) and its review of primary prevention strategies, its ongoing research on effective prevention, the bystander-intervention model, and the importance of developing evidence-based sexual assault prevention programming. Thus it is fair to say that as activists and policy makers call for "comprehensive prevention strategies" (DeGue, 2014, pp. 34) the majority of these efforts will adopt the CDC's public health model. In this model,

${ }^{1}$ For a summary of these legal tools used to address campus sexual assault, see Heldman \& Dirks, 2014. See also American Council on Education (2014), which explains that "under VAWA, new students and new employees must be offered 'primary prevention and awareness programs' that promote awareness of rape, acquaintance rape, domestic violence, dating violence, sexual assault, and stalking” (p. 3). 
(C)2015 Martha McCaughey \& Jill Cermele

Forthcoming in Trauma, Violence, \& Abuse

programming focuses on distal, and some proximal, variables that are implicated in the crisis of sexual assault on college campuses: rape myths; norms around dating and relationships; definitions of consent, and bystander-intervention training. The CDC considers these — and any efforts that target risk and protective factors before violence occurs - to be "primary prevention," and primary prevention is where attention and resources are focused.

Primary prevention is a critical term in the public health model, and prevention is understood as happening at different levels: primary, secondary, and tertiary. According to the CDC (2004), primary prevention is defined as "[a]pproaches that take place before sexual violence has occurred to prevent initial perpetration or victimization" (p. 3), while secondary prevention is defined as "[i]mmediate responses after sexual violence has occurred to deal with the short-term consequences of violence" (p. 3; emphasis added). Tertiary prevention is defined as "[1] ong-term responses after sexual violence has occurred to deal with the lasting consequences of violence" (p. 3). Although the CDC does not dispute the importance of secondary and tertiary intervention, it makes it clear that its focus - and funding - is geared toward primary prevention strategies.

The CDC does not include self-defense — training in it or doing it when assaulted — in any of their materials applying the public health model to sexual assault prevention. A CDC (2004) report states plainly, and erroneously, "There is a lack of research on protective factors so no such examples are presented in the model" (p. 4). ${ }^{2}$ Neither college campuses nor the CDC

${ }^{2}$ The CDC has since that statement declared that they just don't deal with protective factors for anyone other than perpetrators. Their website refers browsers to a World Health Organization (WHO) statement about violence against women worldwide (not related specifically to college 
(C)2015 Martha McCaughey \& Jill Cermele

Forthcoming in Trauma, Violence, \& Abuse http://tva.sagepub.com p. 5

whose public health model they look to for guidance present self-defense as part of comprehensive sexual assault prevention programming. According to Rozee and Koss (2001), most rape prevention programming has targeted both men and women with the goal of increasing knowledge and understanding of rape and decreasing false beliefs and supportive attitudes about

students). In that WHO report, one can find a list of "Factors increasing women's vulnerability," which is worth quoting in full here:

One of the most common forms of sexual violence around the world is that which is perpetrated by an intimate partner, leading to the conclusion that one of the most important risk factors for women — in terms of their vulnerability to sexual assault—is being married or cohabiting with a partner. Other factors influencing the risk of sexual violence include:

--being young;

--consuming alcohol or drugs;

--having previously been raped or sexually abused;

--having many sexual partners;

--involvement in sex work;

--becoming more educated and economically empowered, at least where sexual violence perpetrated by an intimate partner is concerned;

--poverty. (Krug, Dahlberg, Mercy, Zwi, \& Lozano, 2002, p. 175)

The WHO report then explains a wide range of ways to address inequality and laws that are, in some parts of the world, so sexist that college sexual assault would be considered a problem of the privileged. 
(C)2015 Martha McCaughey \& Jill Cermele

Forthcoming in Trauma, Violence, \& Abuse

http://tva.sagepub.com

p. 6

rape - not with the goal of helping those targeted learn how to fight back. Indeed, more

typically, campuses hold speak-outs and events featuring victim testimonials, public displays

such as the Clotheslines Project, and performance art events such as The Vagina Monologues,

which raises money through the V-Day Campaign to help stop violence against women-and do

not hold visible events to train women to thwart their attackers. Some campuses have developed

GPS-based apps that give women a way to contact their friends if they're being attacked or that

provide victim resources and hotlines. All of those efforts have in common an emphasis on

teaching men and women that sexual assault is (a) common, (b) illegal, (c) bad for the victims,

and (d) a crime for which the university provides counseling and even court-style redress.

However, none of these efforts emphasize training women in the tactics of self-defense or even letting them know that their use of force against another person in self-defense is not only possible but a legal right recognized in each of the United States. ${ }^{3}$ A person in the U.S. is

${ }^{3}$ Like all legal rights in the U.S., those with the most privilege can more easily and freely exercise their rights. Self-defense, like any other matter that goes through the U.S. criminal justice system, is interpreted, defended, and/or prosecuted in ways that give Whites a comparative advantage over people of color and men a comparative advantage over women (see Barak et al., 2015; Zatz, 2000). Race, class, gender, and sexual orientation all shape who is considered an aggressor and which responses are considered reasonable responses to that aggression. The case in the news of four African-American lesbian women, labeled in the media as "killer lesbians" (Italiano, 2007) and the "lesbian wolf pack" (Martinez, 2007), who were convicted of gang assault after defending themselves against an African-American man who verbally harassed them, threatened them with rape, and physically assaulted them, reminds us 
(C)2015 Martha McCaughey \& Jill Cermele

Forthcoming in Trauma, Violence, \& Abuse

privileged to defend him or herself, using a reasonable degree of force, from the unlawful and immediate violence of another person (Dix, 2010), and in cases of rape the law clearly condones resistance short of homicide (Kates \& Engberg, 1982, p. 873). Moreover, a significant body of research on women's self-defense training and use to thwart sexual assault confirms its effectiveness. We review this research next, showing how self-defense-doing it when assaulted and training in it - is effective both for individual women and for challenging broader cultural norms that fuel rape culture. After that, we go on to show how self-defense, despite its efficacy, is excluded from working definitions of "primary prevention" in campus RPE programming.

\section{The Efficacy of Self-Defense}

When campus RPE programs address the problem of sexual assault, they often focus on two things: the presence of alcohol as a risk factor, and the presence of other people as a protective factor. For example, the use of alcohol correlates positively with rape completion (see Abbey, 2002; Testa \& Livingston, 2009), and students, particularly women, are often warned to avoid intoxication (or alcohol altogether), to closely monitor their beverages, and to be aware that men might seek to get them drunk in order to more easily gain sexual access to them. With regard to protective factors, rape is less likely to be completed when other people are present (Clay-Warner, 2002), and women are often warned against being alone, and encouraged to travel in groups.

that despite the letter of the law, self-defense is treated as a privilege not available to everyone. Importantly, though, the biases of the criminal justice system are no reason to keep women from the knowledge of their legal right to defend themselves against an impending injury or equate the harm of a completed attack with the possible harm of a possible criminal trial. 
(C)2015 Martha McCaughey \& Jill Cermele

Forthcoming in Trauma, Violence, \& Abuse http://tva.sagepub.com

p. 8

However, rarely are people informed that active resistance, or self-defense, is a way to protect themselves against sexual assault, despite the fact that studies repeatedly show that active resistance, or self-defense, works to thwart attackers in the majority of situations (e.g., Ullman, 1997, 2007). The term "self-defense" is broad, and includes a range of behaviors, both verbal and physical, which a person enacts with the goal of articulating and maintaining bodily and psychological safety and integrity. For example, a knee to the groin or a palm strike to the nose would be obvious physical self-defense techniques used to thwart an illegal act against one's person, but so would a strong, squared-off body stance with eye contact and hands raised up to create distance and protect one's body. Similarly, yelling "No!" and "Back off!" are techniques of verbal resistance, but so is the use of clear, directive language to set a boundary, such as saying, "I like you, but I'm not comfortable taking my clothes off, and so I'm going to keep them on." One analysis of NCVS data, for example, showed that women's use of any form of selfprotective action resulted in an $87 \%$ reduction in the probability of completed rape (ClayWarner, 2002). A more recent analysis of the NCVS data demonstrated similar findings: resistance, both verbal and physical, reduced the likelihood of rape completion without posing the risk of additional injury to victims; there was essentially no difference in injury rates between those who resisted and those who did not, but those who resisted were between $80 \%$ and $86 \%$ less likely to be raped (Tark \& Kleck, 2014).

In their recent article reviewing 25 years of research on the effectiveness of verbal and physical resistance to sexual assault, Gidycz and Dardis (2014) showed that women's resistance to assault is positively correlated with rape avoidance, and that in certain situations (such as public venues), verbal resistance was effective against physically aggressive unwanted sexual contact. Some studies report that forceful verbal insistence in an assault is best matched by 
(C)2015 Martha McCaughey \& Jill Cermele

Forthcoming in Trauma, Violence, \& Abuse http://tva.sagepub.com p. 9

forceful verbal self-defense and that physical force in an assault is best matched by forceful physical self-defense (see Gidycz \& Dardis, 2014). Nonforceful verbal resistance-reasoning, crying, begging — was found to be less effective in thwarting an attack in some studies (e.g., Ullman, 1997; Ullman \& Knight, 1993), but in one study found to be equally effective in thwarting attack at least when combating unwanted fondling in public settings (see Gidycz \& Dardis, 2014). There were certain situations where women may have experienced more challenges in using resistance strategies, such as when the perpetrator was someone they knew or when the women had consumed alcohol. These findings highlight both the effectiveness of women's resistance against sexual assault and the need for self-defense training that includes the most likely contexts in which sexual assaults take place.

In addition to showing the effectiveness of employing self-defense techniques in an actual assault, other studies have compared outcomes for girls and women who took self-defense training and girls and women who did not. Although specific techniques or training methods vary, self-defense scholars agree that self-defense training that is effective and empowering for women should include a number of key components, including: discussions of violence in social rather than individual contexts; a clear framing of perpetrators, not victims, as responsible for assaults; the creation of supportive, non-judgmental environments; instruction in and enactment of powerful and effective physical techniques and specific and effective verbal strategies (Thompson, 2014). A number of studies offer data on self-defense training that includes these components, and show that self-defense training results in an increased likelihood to thwart attacks effectively.

For example, Hollander (2014) found that college women who took a self-defense course were less likely to experience sexual assault later than a comparison group of women with no 
(C)2015 Martha McCaughey \& Jill Cermele

Forthcoming in Trauma, Violence, \& Abuse http://tva.sagepub.com p. 10

such training. The self-defense course was modeled after a program called Assess, Acknowledge, Act (see Rozee \& Koss, 2001), and included components consistent with Thompson's (2014) description of optimal self-defense training for women; participants were trained in both physical and verbal personal safety strategies and also participated in a feministbased academically-oriented discussion regarding violence against women. Women who were trained in self-defense were less likely than a comparison group with no self-defense training to report sexual assault at one-year follow-up, and no women who had trained in self-defense reported a completed rape, compared to $2.8 \%$ of the comparison group. In addition, the qualitative data indicated that a number of women reported using specific physical and verbal self-defense techniques they had learned in the course to thwart an assault.

A larger-scale study of college women who went through an empowerment self-defense program in Canada found significant success in thwarting sexual assaults and a decreased rate of attack. Senn et al. (2015) examined the effectiveness of a program called Enhanced Assess, Acknowledge, Act (based also on the program by Rozee \& Koss, 2001). As the name suggests, participants are taught to assess for individual and situational cues that indicate a risk for sexual assault, to be able to acknowledge those risks in spite of the challenges posed by socialization and emotional difficulties, and then to act powerfully to protect themselves against assault. In addition, the program focuses on increasing women's understanding of their own sexual desires and boundaries, and how to set and maintain those. Participants in the study, at 12 months after the training began, had reduced their risk of completed sexual assault by $46 \%$ compared to the control group, which had received a brochure about sexual assault. Participants who took the resistance training had also reduced their risk of attempted assault by $63 \%$ compared to the control group. Furthermore, women who were trained in self-defense had a better understanding 
(C)2015 Martha McCaughey \& Jill Cermele

Forthcoming in Trauma, Violence, \& Abuse

http://tva.sagepub.com

p. 11

of their risk for acquaintance rape and reported higher self-efficacy for self-defense, including forceful verbal and physical strategies. The benefits of this training, then, extended beyond beliefs and intent; this study shows that self-defense training is a protective factor against sexual assault (Senn et al., 2015; Senn \& Hobden, 2015).

In another longitudinal study, Sinclair et al. (2013) found that a six-week "No Means No Worldwide" self-defense program for high school girls ${ }^{4}$ in a high-risk area of Nairobi, Kenya was effective for thwarting sexual assault. A total of 522 girls completed surveys at baseline, and 489 at a 10 -month follow-up. While $25 \%$ of the girls reported experiencing completed sexual assault in the prior year (90\% of the assaults being by someone known to them), those who received the self-defense course saw the incidence of completed sexual assault decrease from $25 \%$ at baseline to $9 \%$ at follow-up. In contrast, the percentage of completed sexual assaults remained unchanged for a control group, which had been given the current nationalstandard, one-hour course for adolescents on sexuality and gender-based violence, and which includes no specific strategies to prevent sexual assault. Over half the girls in the self-defense group reported having used the self-defense skills to successfully thwart a sexual assailant in the year after the training (Sinclair et al., 2013, p. 377). Of these, 50\% used verbal skills alone to stop the attack, $33 \%$ started with verbal skills and added physical skills, and $17 \%$ used physical skills alone. While this study did not show the decrease in attempted sexual assaults that the Canadian study did, it showed that self-defense training was correlated with a significant increase in girls' ability to thwart sexual assaults.

\footnotetext{
${ }^{4}$ For an overview of the No Means No Worldwide self-defense curriculum see Sinclair et al. (2013, p. 376) and http://nomeansnoworldwide.org.
} 
(C)2015 Martha McCaughey \& Jill Cermele

Forthcoming in Trauma, Violence, \& Abuse

http://tva.sagepub.com

p. 12

Self-defense training not only increases women's chances of thwarting sexual assault but is also linked to positive well-being outcomes. In a review of the literature, Brecklin (2008) reported that women who participated in self-defense training described feeling stronger, more assertive, and more efficacious. The data on the impact of self-defense training in other areas, such as fear, perceived vulnerability, and self-esteem was mixed, with only some studies reporting changes in these variables (Brecklin, 2008). However, these data warrant further study; it may be that higher levels of fear and perceived vulnerability, while unpleasant affective states, reflect an awareness of the risk of assault, rather than an incapacitating emotional state. That women report feeling stronger and more efficacious after self-defense training could mean that the increased fear is not necessarily experienced as paralyzing.

As women experience their bodies in new ways through self-defense training, they experience an increase in self-efficacy; self-efficacy has been found to be positively linked to other health-protective behaviors including improvement in a range of emotional and psychological domains, such as decreased levels of depression, anxiety, hostility, and fear, and increased levels of assertiveness, self-esteem, perceived control, and global and physical selfefficacy (Brecklin, 2008; Brecklin \& Ullman, 2005; Ozer \& Bandura, 1990). Self-defense training, overall, is empowering for women (Cermele, 2010; McCaughey, 1997; Orchowski, Gidycz, \& Raffle, 2008; Ozer \& Bandura, 1990; Senn, 2011). Research also shows that neither self-blame nor victim-blaming increase with self-defense training (Gidycz \& Dardis, 2014).

Self-defense training is not just empowering for individual women but transformative of the gender ideology that supports rape culture - whether or not a woman actually has to use it to thwart an attack. Self-defense training empowers women and upsets the rape culture's scripts of gendered bodies that make rape relatively easy for men to accomplish and rationalize. When 
(C)2015 Martha McCaughey \& Jill Cermele

Forthcoming in Trauma, Violence, \& Abuse http://tva.sagepub.com p. 13

women train for self-defense against the violence perpetrated against them, they perform a set of behaviors that not only can effectively thwart a sexual assault, but systematically, and systemically, challenge the status quo: that women's bodies are inherently rapeable, and that men, and only men, have the power to make that choice about women's bodies (Hollander, 2009, 2013; McCaughey, 1997). Self-defense training helps women rewrite sexist social scripts and challenge the ideologies underlying rape culture by making explicit the fact that women's bodies are not simply there for men's taking, or protecting.

Furthermore, self-defense training is an approach of strength-based, rather than victimbased, activism, education, and resistance. As Thompson (2014) points out, self-defense training based in feminist principles of empowerment and gender equity impact more than women's ability to thwart an attack. Self-defense training teaches women about their own value and strengths. In addition, a feminist self-defense program reminds women that violence takes place in social contexts, and shifts women's experiences of their gendered bodies (McCaughey, 2007; Thompson, 2014). While more research is needed on intersectionality in self-defense training, researchers are starting to pay attention to how women from different racial and ethnic groups learn and experience self-defense (e.g., see Speidel, 2014), but also on how women need to learn self-defense as women.

Despite the effectiveness of self-defense in thwarting attack, and the culture-changing impact of women's self-defense training, colleges and universities remain reluctant to emphasize it. The reasons for this "resistance to resistance" have themselves been studied (see Cermele, 2010; Hollander, 2009). There is overwhelming sentiment among feminists that we ought to "teach men not to rape" - but as Gidycz and Dardis (2014) point out, there is simply no data 
(C)2015 Martha McCaughey \& Jill Cermele

Forthcoming in Trauma, Violence, \& Abuse

http://tva.sagepub.com

p. 14

supporting the idea that efforts such as consent education are successful in reducing perpetration on campus.

The CDC states that the social and cultural norms that "maintain women's inferiority and sexual submissiveness" constitute a risk factor for sexual assault perpetration (Veto Violence, Principles of Prevention, Centers for Disease Control, n.d.). Accordingly, by this definition, selfdefense training should be considered primary prevention precisely because training women in self-defense techniques significantly challenges those cultural norms. In its effort to seat responsibility for preventing violence with the perpetrators rather than the victims, the CDC misses a critical opportunity to make available the well-documented data on the effectiveness of self-defense in reducing the likelihood of completed assaults, which also reduces the consequences and burdens experienced by individuals and society as a whole. The CDC's position that the empirical literature points to no protective factors for women is inconsistent with the data that indicate the efficacy of resistance in thwarting an attack, despite the fact that these studies clearly meet the criteria of being "evidenced-based". Tragically, ignoring the data on the effective and empowering results of self-defense training ultimately robs women and college campuses of the information they need to change the rape culture and reduce the number of rapes on campus.

While of course preparation to resist sexual assault and self-defense training provides no guarantee of stopping an attack, it certainly increases dramatically the likelihood of doing sojust as learning to swim increases dramatically, but does not guarantee, a person's likelihood of staying alive in deep water. Now that rape prevention education is a government mandate, and research has established the efficacy of self-defense, it is important to examine whether selfdefense is being included in the public health model of sexual assault prevention. The discourse 
Forthcoming in Trauma, Violence, \& Abuse http://tva.sagepub.com p. 15

of sexual assault prevention actually reveals a fundamental tension surrounding of the concept of "prevention." In the following section we explain the public health model guiding RPE and trace what "prevention" means to those shaping the policies and funding streams for campus sexual assault prevention today, showing how it has increasingly come to exclude self-defense.

\section{The Public Health Model of Sexual Assault Prevention}

The CDC's public health model starts with a problem and then identifies relevant risk and protective factors; based on this, it develops a prevention strategy, which it assesses for effectiveness along the way, and then works to ensure widespread adoption of the effective prevention approach. A protective factor is defined as a "characteristic that decreases the likelihood of a person becoming a victim or perpetrator of violence because it provides a buffer against risk" (CDC, 2004, p. 3; also Public Health Approach to Violence Prevention, 2014, para. 5). The CDC (2004) applies this model to sexual assault prevention with the following description:

population-based and/or environmental and system-level strategies, policies, and actions that prevent sexual violence from initially occurring. Such prevention efforts work to modify and/or entirely eliminate the events, conditions, situations, or exposure to influences (risk factors) that result in the initiation of sexual violence and associated injuries, disabilities, and deaths. Additionally, sexual violence prevention efforts address perpetration, victimization, and bystander attitudes and behaviors, and 
seek to identify and enhance protective factors that impede the initiation of sexual violence in at-risk populations and in the community. (p. 1$)^{5}$

Since the CDC has been tapped by the White House Task Force, the CDC's public health framework for sexual assault prevention guides the specific models for campuses and local agencies engaged in RPE. Taking the stance that violence against women is preventable, the CDC's 2004 document on the public health approach to sexual assault prevention offers the following analogy, which we quote in full:

One day, a fisherman was fishing from a river bank when he saw someone being swept downstream, struggling to keep their head above water. The fisherman jumped in, grabbed the person, and helped them to shore. The survivor thanked the fisherman and left, and the hero dried himself off and continued fishing. Soon he heard another cry for help and saw someone else being swept downstream. He immediately jumped into the river again and saved that person as well. This scenario continued all afternoon. As soon as the fisherman returned to fishing, he would hear another cry for help and would wade in to rescue another wet and drowning person. Finally, the fisherman said to himself, "I can't go on like this. I'd better go upstream and find out what is happening."

\footnotetext{
${ }^{5}$ In 2004 the CDC may very well have been responding to the fact that the overwhelming amount of resources went into servicing victims and prosecuting assailants, and far fewer to preventing sexual assault in the first place. Nonetheless, the 2004 document is an active link on the CDC web page for sexual violence prevention, and it is the current framework on offer.
} 
(C)2015 Martha McCaughey \& Jill Cermele

Forthcoming in Trauma, Violence, \& Abuse

http://tva.sagepub.com

p. 17

Furthering this analogy, the CDC (2004) argues that its efforts at prevention should be positioned "at the top of the river: building safe passages and keeping people from being pushed into the river."

The CDC currently has an online training module on violence prevention called "Principles of Prevention" (“POP”) and after going through this 90-minute educational website, users can take a "POP Quiz," on some or all types of violence, including sexual violence (Veto Violence, Principles of Prevention, Centers for Disease Control, n.d.). The trainee is offered information on the definitions, burdens, consequences, risk factors, and protective factors for each type of violence, and then provided information on primary, secondary, and tertiary intervention. Next, information is provided on a social-ecological model of violence, which situates individuals who commit acts of violence in individual, relational, community, and societal contexts. Finally, the viewer is educated on the public health approach and the steps within a public health approach to prevent violence. The CDC's Principles of Prevention make it clear that the goal is to prevent first-time perpetration of violence, and the information provided-including risk and protective factors--focuses on what puts individuals at risk for, or protects individuals from, committing acts of sexual violence.

The focus on victims and survivors is largely in the sections on burdens and consequences, with the framework that consequences to individuals are also felt by society as a whole (Veto Violence, Principles of Prevention, Centers for Disease Control, n.d.). In relegating information about victims of violence to sections on consequences, the $\mathrm{CDC}$ communicates that no information or resources are available on the ways in which potential victims might be able to prevent--i.e., to protect themselves--from sexual violence. Indeed, despite the growing number of studies documenting the effectiveness of self-defense, a video clip in the section on protective 
(C)2015 Martha McCaughey \& Jill Cermele

Forthcoming in Trauma, Violence, \& Abuse http://tva.sagepub.com p. 18

factors features a researcher who states that, “...[R]ight now, the empirical literature cannot point to anything that says if you have this, this will make it less likely that you will be sexually assaulted" (Veto Violence, Principles of Prevention, Centers for Disease Control, n.d.).

According to the CDC, then, self-defense is not a protective factor in the public health model of sexual assault prevention. We thus turn now to a broader review of what currently counts as primary prevention to show that self-defense training is excluded. We then consider the consequences of the consistent framing of self-defense as a "downriver" solution that is not part of primary prevention.

\section{Current Interpretations of the Primary Prevention Charge}

All activists, practitioners, policy makers, and educators agree that sexual assault on college campuses is a problem that we want to prevent. In addition, there appears to be widespread agreement that self-defense, and self-defense training, are not primary prevention strategies - even among those who have seen the data on its effectiveness for thwarting assaults. If self-defense is mentioned at all, it is relegated to other, less-prioritized categories in the public health model, which, in its application to sexual assault prevention, positions self-defense as a secondary intervention at best.

According to the CDC (2004),

The most common prevention strategies currently focus on the victim, the perpetrator, or bystanders. Strategies that aim to equip the victim with knowledge, awareness, or selfdefense skills are referred to as risk reduction techniques. Strategies targeting the perpetrator attempt to change risk and protective factors for sexual violence in order to reduce the likelihood that an individual will engage in sexually violent behavior. The goal of bystander prevention strategies is to change social norms supporting sexual 
(C)2015 Martha McCaughey \& Jill Cermele

Forthcoming in Trauma, Violence, \& Abuse http://tva.sagepub.com p. 19

violence and empower men and women to intervene with peers to prevent an assault from occurring. Other prevention strategies may target social norms, policies, or laws in communities to reduce the perpetration of sexual violence across the population. (emphases added)

Here self-defense skills are framed as "risk reduction" while bystander intervention strategies are clearly positioned as primary prevention. Thus, while self-defense logically fits in the same category as bystander intervention, and does not actually parallel the medical or psychological help that schools offer after a completed attack, it is nevertheless positioned as secondary rather than primary prevention.

The CDC is not alone in its choice to frame self-defense as secondary rather than primary prevention. In late 2013, V-Day, the organizing structure for the benefit productions of The Vagina Monologues, partnered with Students Active for Ending Rape (SAFER) to launch a Campus Accountability Project. Accountability was assessed in part by a score on the rubric/assessment tool they developed; over $80 \%$ of the 300 U.S. college sexual assault policies they examined earned a grade C or lower (SAFER \& V-DAY 2013b), suggesting there are significant improvements that these schools could make in their policies aimed at preventing sexual assault. However, in their rubric self-defense training is relegated to the "safety/riskreduction" or secondary prevention category, and therefore is not even calculated into the grade campuses earn for their primary prevention policies. One of the report's recommendations is for colleges to "increase primary prevention efforts and create more opportunities for students to engage meaningfully with primary prevention activities." Because SAFER's (2013a) concept of "primary prevention" does not include self-defense training, schools that currently offer selfdefense training to their students might still be considered negligent in their primary prevention 
(C)2015 Martha McCaughey \& Jill Cermele

Forthcoming in Trauma, Violence, \& Abuse http://tva.sagepub.com

p. 20

education, and schools that chose to add self-defense training to their RPE programs would see no improvement in their scores, despite the data on the efficacy of self-defense training in reducing rates of sexual assault on college campuses (Senn et al., 2015). ${ }^{6}$

V-Day has raised millions of dollars in its "stop the violence" campaign but hardly any of that money has gone to empowering women to stop the violence precisely when it is directed at them. Information about self-defense is excluded from the V-Day Campaign's public educational materials and self-defense organizations are excluded from its list of suggested recipients of money raised by campus productions of The Vagina Monologues. V-Day made its aversion to self-defense training clear when they explained that self-defense, even if it stops violence against women, uses violence to do so and is thus counter to their agenda (McCaughey, 2013).

Another well-known organization focusing on sexual assault prevention is the California Coalition Against Sexual Assault (CALCASA). CALCASA has a comprehensive website (see http://www.calcasa.org/)--and a seat at the table when the CDC draws up its list of

${ }^{6}$ SAFER (2013a) looks at safety initiatives and counts how many colleges have security systems in dorms, blue lights on campus, and "risk reduction programming." However, unlike what they deem "primary prevention" programming, they do not say whether self-defense counts in this or not-just that $92.3 \%$ of the colleges provide some type of risk-reduction programming. Their problem with risk reduction programming is, as they put it, "this unfairly places the burden of prevention on potential victims [and] [i]nstead colleges and universities should prioritize primary prevention programs and supplement those programs with risk reduction efforts" (SAFER \& VDay, 2013a, p. 15). 
(C)2015 Martha McCaughey \& Jill Cermele

Forthcoming in Trauma, Violence, \& Abuse http://tva.sagepub.com

recommendations for college campuses to follow. CALCASA engages in statewide social marketing campaigns and trainings that include the "My Strength" campaign for high school boys, aimed at preventing the first-time perpetration of sexual violence. The "My Strength" campaign posters offer boys and men images of young men saying, "My strength is not for hurting" and then following with specifics such as, "So when she said to stop, I stopped." (California Commission Against Sexual Assault, n.d., "My Strength"). In addition, like many other RPE programs, CALCASA champions the Green Dot program, which is a bystander intervention program; in framing "My Strength" and "Green Dot" as its primary prevention strategies, the targets for training and resources are men and bystanders as potential not-rapists, but not women as potential thwarters of rape.

CALCASA's website includes self-defense in its pull-down menu under the category "Prevention," citing academic research studies that show the effectiveness of self-defense for thwarting an attack and suggesting that empowering, feminist self-defense training can be a good thing. However, CALCASA stops short of positioning self-defense as primary prevention. In fact, CALCASA makes of point of noting that self-defense training is not primary prevention: CALCASA promotes the development of comprehensive prevention programming that includes primary, secondary and tertiary prevention efforts. In the last 10 years there have been many efforts to highlight primary prevention strategies. However it remains important to recognize that secondary and tertiary prevention efforts are also necessary components of those comprehensive prevention strategies in order to meet each communities' needs. CALCASA believes in the value of Feminist Empowerment Based Self Defense Program Models as part of the continuum of prevention strategies that communities use to create a 
(C)2015 Martha McCaughey \& Jill Cermele

Forthcoming in Trauma, Violence, \& Abuse http://tva.sagepub.com p. 22

comprehensive approach to addressing and preventing sexual violence. (California

Commission Against Sexual Assault, n.d., "Self-Defense”, emphasis added).

Clearly, some organizations, like CALCASA, are not against including self-defense training as part of a comprehensive sexual violence prevention effort. This shows that even those who understand the data on the effectiveness of self-defense against sexual assault nevertheless frame it as something other than the primary prevention in which they are now legally mandated to engage.

It should not be surprising, then, that some students can find self-defense courses on their campuses, framed not as primary prevention but as safety or risk reduction--most notably, the Rape Aggression Defense (RAD) courses offered by campus police departments and, occasionally, a physical education or even an academic course on self-defense. For example, Drew University offers a psychology seminar on gender violence and women's resistance that begins with a 20-hour empowerment self-defense course (Cermele, 2004). At Northeastern Illinois University self-defense is a one credit-hour course taught in the Women's and Gender Studies Program (Thompson, personal communication). However, those courses are not presented by their universities among their primary prevention programming, and so they do not "count" as part of the RPE programming that is now mandatory on U.S. campuses receiving federal funds. Indeed, training in and enactment of self-defense remains notably absent from the otherwise excellent primary prevention agenda.

\section{Lifeguards at the Top of the River: Bystander Intervention Programs}

Bystander intervention campaigns have become de rigeur on college campuses for sexual assault prevention education. Bystander intervention is mentioned explicitly in the recommendations of the White House Task Force and is there positioned as a form of primary 
(C)2015 Martha McCaughey \& Jill Cermele

Forthcoming in Trauma, Violence, \& Abuse http://tva.sagepub.com

p. 23

prevention. In bystander intervention programs, college students are addressed as witnesses to sexual assault attempts and are encouraged to distract the would-be assailant and/or take the would-be victim away to a safe place. However, no information is provided to the likely victims about how to intervene on their own behalves as their own active bystanders (i.e., defend themselves) in cases where they are alone with their assailant(s).

A handful of bystander intervention programs have received strong, positive media attention. The Bringing in the Bystander ${ }^{\circledR}$ program, developed and offered through the University of New Hampshire, was named by the White House Task Force as a model program for sexual assault prevention (see Not Alone, 2014). One aspect that makes this program unique is the degree to which it is grounded in research (Banyard, Plante, \& Moynihan, 2004); it has been found effective in facilitating positive and desired changes in bystander attitudes and intended behaviors (Banyard, Moynihan, \& Plante, 2007 Moynihan, Banyard, Arnold, Eckstein, \& Stapleton, 2010, 2011), and in one pilot study with military personnel, self-reported actual behaviors (Potter \& Moynihan, 2011).

The Green Dot program, offered through the Violence Intervention and Prevention Center at the University of Kentucky (Green Dot, 2014), intends to engage bystanders "through awareness, education, and skills practice, in proactive behaviors that establish intolerance of violence as the norm, as well as reactive interventions in high-risk situations-resulting in the ultimate reduction of violence" (quoted by CALCASA; California Commission Against Sexual Assault, n.d., “Green Dot”). Like Bringing in the Bystander ${ }^{\circledR}$, Green Dot is identified as a primary prevention approach. Green Dot seeks to spark a culture shift by identifying early adopters, or popular opinion leaders, in various settings (i.e. high schools, colleges, community groups) "and providing them with the tools they need to intervene when they witness acts of 
(C)2015 Martha McCaughey \& Jill Cermele

Forthcoming in Trauma, Violence, \& Abuse http://tva.sagepub.com

power-based personal violence. Green Dot establishes the new norm of integrating prevention into daily activities and personal relationships" (quoted by CALCASA; California Commission Against Sexual Assault, n.d., "Green Dot”, emphasis added). Cook-Craig et al. (2014) state that as a bystander program, Green Dot is clearly positioned as a method of primary prevention in a public health framework, due to its ". . . likelihood of not just individual change but also community and social norms change, as the target population for change is everyone in the community, rather than just perpetrators or victims" (p. 1167, emphasis added).

The bystander programs, however, are not grounded in any empirical data supporting their efficacy in either reducing the incidence and prevalence of sexual assault, or in changing community and social norms around sexual violence. The studies on the Bringing in the Bystander ${ }^{\circledR}$ program, while interesting, are entirely based on self-report, with two of the three outcome studies showing an increase in participants' future intent to intervene, and only one where participants reported that they actually had intervened. Despite the lack of definitive empirical data showing that these programs work to stop sexual assaults that are either about to begin or in progress, they are held as the standard for cutting-edge RPE. Moreover, providing those same interventionist strategies to the individuals targeted for violence is relegated to the less-prioritized category of secondary prevention. Thus framing bystander invention as the best or only primary prevention strategy in the face of imminent sexual assault is based neither in logic nor empirical research.

As important as bystanders can be in identifying and addressing the green dots and red flags, bystander training cannot effect the changes in women's sense of agency that self-defense training accomplishes. The benefits of self-defense training, then, go beyond what bystander intervention programs can offer and work to prevent assault at the same point along the river. 
(C)2015 Martha McCaughey \& Jill Cermele

Forthcoming in Trauma, Violence, \& Abuse

http://tva.sagepub.com

p. 25

Women who train in self-defense move around the world differently. They are more aware of their surroundings, their bodily boundaries, their capabilities, and their limits (McCaughey, 1997). They are likely more empowered to acknowledge and respond to the green dots and red flags around them; such awareness and response, not only when sexual assault is imminent but also when boundaries are being violated in early, "grooming" stages, is a critical component of the curriculum in empowerment-based self-defense training (Thompson, 2014).

The continued framing of men as seekers of sex and as physically capable of "taking" it (usually from women but sometimes from other men as well), whether through programs designed to change attitudes or engage bystanders, perpetuates the sense of male strength and power that only the embrace of women's self-defense can undermine. Girls and women are left viewing these campaigns as the ones who are acted upon benevolently--or acted upon maliciously, if the RPE messages don't work to reach potential perpetrators or bystanders. This is reminiscent of the campaign that put stickers in the urinals that gave men the message that "You're holding the power to stop rape in your hands." Such messages, unfortunately, also teach men that they are holding the power to rape in their hands. This same message is conveyed in the "My Strength" campaign, referenced earlier, which reaches men in an attempt to stop them from assaulting by offering them a model of how to take no for an answer. It speaks to men as a biological group whose anatomical parts enable the problem of rape, naively situating rape as a biologically based problem rather than a social and political problem. This is underscored by the lack of posters addressed to women about HER strength, which would be easy enough to create, such as: "My strength can be used for self-protection"; "My strength can be used against you"; or "My strength isn't just academic". 
UNH's Bystander posters (which are available for purchase ${ }^{7}$ ) offer a wider range of messages about sexual assault prevention than simply reminding men of their physical power relative to that of women's; however, while the messages offer unequivocal definitions of rape, and model both men and women labeling those behaviors appropriately and actively intervening as bystanders, they nonetheless convey the message that only men, and bystanders, can prevent sexual assault (Bystander Store Posters, 2014); no posters available on the website show women targeted for sexual assault engaging in verbal or physical resistance strategies. Thus, as a method of primary prevention in the focus on changing attitudes, two things happen: first, by reinforcing the myth of men's inherent superiority relative to women, the attitudes that support and maintain rape culture are underscored and reinforced, rather than challenged; and second, if attitude change is occurring, it is a move to a kinder, gentler sexism, rather than a move from sexism to equality.

Bystander programs surely work in some situations, but as the method of campus rape prevention, they miss the important component of empowering women. They also miss getting men to take women seriously as equals, rather than as damsels in distress, thereby continuing to give men the power in the situation. At best, they promote a model of masculine selfless gallantry; at worst, they promote the current discourse that only men are in charge of whether or not rape happens.

Furthermore, the techniques described by bystander programs actually do little to effect change in community attitudes about rape. For example, training materials and role-plays often depict scenarios showing men distracting potential rapists from their intended victim, rather than showing men directly challenging behaviors that have been identified as aggressive precursors to

\footnotetext{
7 See http://cola.unh.edu/prevention-innovations/bystander-store-posters.
} 
(C)2015 Martha McCaughey \& Jill Cermele

Forthcoming in Trauma, Violence, \& Abuse

http://tva.sagepub.com

p. 27

assault. Similarly, scenarios depicting women as bystanders often show women removing their female friends from potentially dangerous situations without directly labeling or challenging those acting aggressively. Such bystander behaviors, while undoubtedly valuable in promoting the safety of individuals targeted for assault in the moment, do little if anything to fulfill the primary prevention goal of community attitude change.

Despite some of the problems with bystander intervention training as it is typically conceptualized and implemented, we embrace encouraging and training bystanders to recognize and intervene when they witness the signs of imminent assault or an assault in progress.

However, we note that bystander intervention and using self-defense work to prevent violence at the same point in time: immediately before or during an act of perpetration. Put another way, self-defense and bystander intervention work at the same point along the river; one is not any more, or less, "upstream" than the other. This suggests that the issue is less a question of upriver vs. down-river solutions, but who is recognized as entitled to be at the top of the river. In the next section we show that the exclusion of self-defense from the primary prevention agenda perpetuates a hidden curriculum that solidifies, rather than dismantles, the gender norms of rape culture and leaves women without the training to thwart an attacker or even the knowledge that fighting back is an option. ${ }^{8}$

8 A decade ago the entry for "rape prevention" in the Encyclopedia of Rape (Smith, 2004) actually included a reference to women's self-defense and yet over the past decade self-defense has gone from marginalized to downright demonized with Internet memes suggesting that one is naive to suggest that women should learn self-defense rather than get men to stop raping, and 
(C)2015 Martha McCaughey \& Jill Cermele

Forthcoming in Trauma, Violence, \& Abuse

http://tva.sagepub.com

p. 28

\section{The Hidden Curriculum of Campus Rape Prevention and Education Programs}

Many of the RPE efforts to protect students' rights around sexual assault paradoxically appear to presuppose an assault has already been completed. For example, the White House's "Not Alone" website's "Know Your Rights" tells students their rights only after a rape is over (Not Alone, 2014a). By neglecting to inform women of their legal right to self-defense, what is communicated, by omission, is that women don't have a right to train to defend themselves, or the right to use self-defensive violence, despite the fact that, by law, they do.

Students who are victimized or accused of perpetrating surely do have rights. Sadly, however, the right to use self-defensive violence is rarely emphasized, and campuses are not interpreting "primary prevention" as a mandate to train in self-defense. When women are told to know their rights, but never told that those rights include the right to defend themselves, they are once again positioned as physically helpless individuals whose only hope is outraged victimhood bent on legal redress.

The hidden curriculum in current RPE efforts offers a number of unintended lessons: that women do not have the right or ability to defend themselves; that women must rely on more powerful males to save/help/rescue them; and that men, but not women, maintain the moral order of their social worlds, because the decision to rape, or not rape, is in the hands and bodies of men. We are left to hope that men use their power benevolently and compassionately, in choosing to respect women's boundaries, that knowing the difference between consent and

widespread public criticisms of the 2014 Miss USA for suggesting more college women should have the option of training in self-defense. 
(C)2015 Martha McCaughey \& Jill Cermele

Forthcoming in Trauma, Violence, \& Abuse http://tva.sagepub.com

p. 29

coercion keeps men on the right side of the law, and that bystanders will be willing and able to step in before a crime has been committed or completed.

Furthermore, the hidden curriculum of RPE offers a set of depoliticized messages that frame sexual assault as a problem of a lack of information (give them the definitions of sexual assault and consent); a problem of a lack of compassion (explain to men that it hurts being a victim); or a lack of positive community role models and norms (explain to men that they have a role to play as upstanding bystanders who step up to intervene). Thus these messages, however helpful in certain ways, when not accompanied by messages about women's ability and right to resist the assault, teach people that once an assault starts, there is nothing the victim can do in the moment other than hope for compassion, empathic listening skills, or intervention by another person. While we agree with rape prevention educators who target men and not women that the problem of sexual assault is morally the perpetrators', we must also embrace his target's moral right and/or physical ability to fight back.

The hidden curriculum ultimately creates benevolent sexism - in which men are framed as the knights in shining armor, swooping in to rescue the damsels in distress. And while, on the surface, this seems far better than the hostile sexism exemplified in rape-supportive statements and behaviors, the work of multiple scholars shows that hostile sexism and benevolent sexism are correlated (e.g., Glick \& Fiske, 2001; Good, 2011; Good \& Rudman, 2010; Lee, Fiske, \& Glick, 2010). Bystander intervention programs, then, when not paired with self-defense training to remind everyone that women targeted for sexual violence can serve as their own bystanders, run the risk of perpetuating the very rape culture they seek to eliminate.

Framing self-defense (training in it and enacting it) as secondary prevention —in a category with victim support, counseling, reporting, legal redress, and campus judicial 
(C)2015 Martha McCaughey \& Jill Cermele

Forthcoming in Trauma, Violence, \& Abuse

http://tva.sagepub.com

p. 30

processes-means that self-defense has been excluded from the many RPE efforts attempting to comply with the new government mandates. This omission results in a hidden curriculum that individualizes the problem of gendered violence, elevates women's vulnerability into a natural state rather than an embodied effect of rape culture itself, and confirms men's sense of power to rape.

\section{Learning How to Swim in the River: Self-Defense as Primary Prevention}

To underscore our argument that self-defense training is primary prevention in the CDC's own public health model, let us provide a few comparisons to other public health models that aim for population-level change. To prevent breast cancer, STDs, HIV, smoking, and teen pregnancy, public health prevention campaigns target the potential victims of the problem and suggest they curb their risk factors or otherwise change their behaviors proactively. In other words, they seek to identify and promote key protective factors that would dramatically impact the problem.

The CDC's National Breast and Cervical Cancer Early Detection Program advocates screening programs, particularly for underserved women. In providing a free mammogram and a free pap test, they are not going after the root of the problem that is causing such a high rate of these cancers, such as toxins in our environment or men spreading HPV by having intercourse without condoms. But the CDC understands those early detection efforts, engaged in by the would-be victims of those diseases, to be preventative. Offering such free health screenings are generally not accused of "blaming the victim" and being "too individualistic." The many female, and feminist, advocates of breast and cervical screening do not worry that they are, nor do they routinely get accused of, implying that if a woman gets cancer it's her own fault because she did not get screened soon enough. They know that screening early increases a woman's chances of 
(C)2015 Martha McCaughey \& Jill Cermele

Forthcoming in Trauma, Violence, \& Abuse http://tva.sagepub.com p. 31

surviving cancer. Self-defense advocacy is completely analogous: we know that self-defense training and fighting back increase a woman's chances of surviving and even thwarting a sexual assault.

Similarly, the prevention of teen pregnancy is considered by the CDC and others as a triumph of the public health model. They attribute reliable birth control, as well as a drop in teen sexual activity, to the massive drop in teen pregnancies and births across the U.S. (Preventing Pregnancies 2014). Had the CDC taken the approach to stopping teen pregnancy that they have been taking to stopping sexual assaults, they would have been telling teens the definition of pregnancy; giving them the frightening statistics on how many teens experience unwanted pregnancies; telling them how it will ruin their lives; telling them to abstain from reproductive sexual encounters; training other people to stop them from engaging in those encounters or showing up just in the nick of time with a condom; and then offering to help girls in a nonjudgmental setting after they become pregnant, and keeping track of their numbers. It would be treating teen girls as if there is nothing they themselves can do to prevent a pregnancy if and when they are sexually active. The CDC acknowledges that the consistent and correct use of birth control among sexually active teens helps prevent teen pregnancy. The CDC would never have failed to provide teens with the tools they needed to prevent the outcome of impregnation at any point along the process that leads to it. Nor would the CDC have regarded the use of birth control to stop a pregnancy as secondary or tertiary prevention rather than as primary prevention of teen pregnancy.

Teaching self-defense, then, is completely consistent with other primary prevention programs the CDC has supported. It is the equivalent of offering free health screenings and teaching birth control. Like these other programs where the efficacy of these primary prevention 
Forthcoming in Trauma, Violence, \& Abuse http://tva.sagepub.com p. 32

techniques has been empirically established, there is documented effectiveness of self-defense training and enactment for thwarting attacks, helping survivors heal and avoid re-victimization, empowering women, and contributing to population-level changes that make self-defense a primary sexual assault prevention strategy in the public health model.

Currently, our models - at all levels, from individual to community and legal levels - try to get men not to rape, or try to get someone other than the potential victim to stop the man from raping before he does it. Similarly, these models, at all these levels, seek to provide services the victim and her family, and to follow medical and legal protocols for helping victims and reporting the crime after the criminal deed has been done. It is crucial to recognize that in addition to a time significantly "before" anyone ever comes near a woman to assault her and the "after" of a completed rape, when a woman is calling a victim's advocate or on her way to the E.R. for a rape kit, there is a time between or during when a woman's sense of entitlement to her bodily boundaries, her knowledge of her options, and her preparedness to execute self-defensive action can facilitate her ability to intervene in and thwart the rape attempt. Intervention between or during meets the criteria for primary prevention. Any point where rape or sexual assault is thwarted before the perpetrators complete their intended crimes is a point of successful prevention: the rapist is prevented from completing the assault. To argue otherwise is to suggest that once a man tries or begins to assault a woman there is nothing she herself can do to change the course of the event. We can and should teach women that they have options just prior to or during an attack, just as bystanders do; we can and should remind women that self-defensive violence is one of their legal rights, just as we remind bystanders that they have the right to intervene. 
(C)2015 Martha McCaughey \& Jill Cermele

Forthcoming in Trauma, Violence, \& Abuse http://tva.sagepub.com

p. 33

In addition, self-defense training can occupy more than one position in the public health model; components and strategies need not be conceptualized and labeled as either primary prevention or something lesser. The utility of self-defense as risk reduction or tertiary intervention in no way negates its appropriateness as a primary prevention strategy. Rosenblum and Taska's work (2014) shows that self-defense can be empowering for survivors of prior attacks. Among this subpopulation, self-defense is both certainly primary prevention and tertiary prevention insofar as it serves to both prevent future acts of victimization (primary) particularly for individuals at risk for revictimization (secondary), and as a trauma intervention/healing for the survivors (tertiary). Intervention, like violence and victimization, is complex, and there is no need to artificially simplify it by a system of categorization that negates or minimizes certain outcomes in favor of others.

All practitioners, policy makers, scholars, and activists agree that our RPE programs should be multifaceted, multilayered attempts to prevent the problem and aid those who have been adversely affected. We all agree that RPE programs should aim to make population-level change rather than helping only those who "are drowning in the river." What we have argued here is that: (1) data support the evidence of the effectiveness of self-defense--so much so, in fact, that it is a wonder that it is not listed as part of legal compliance/right-to-information on the subject; (2) self-defense training is theoretically and practically consistent with the tenets of primary prevention in the public health model; (3) the continued absence of information about and training in self-defense leads to a hidden curriculum in RPE programs that dangerously reinforces men's sense of superiority and women's sense of vulnerability and, in so doing, propels the rape culture that we all want to stop; and (4) training large numbers of women in selfdefense and publicizing both their ability and right to defend themselves would radically 
(C)2015 Martha McCaughey \& Jill Cermele

Forthcoming in Trauma, Violence, \& Abuse http://tva.sagepub.com

p. 34

transform the gender ideologies and assumptions about rape culture to make dramatic cultureshifting, population-level change. Indeed, in the public health model upon which RPE programs increasingly rely, self-defense is a key protective factor in campus sexual assault prevention.

Unlike universities' concerns about legal compliance, reporting incidences of victimization according to proper procedure, sharing the definition and horrid statistical reality of rape, and telling women what to do after a completed rape, training women in self-defense does not individualize the treatment of victim or perpetrator, thereby removing the problem of sexual assault from the broader political and feminist analysis of gendered violence (Lamb, 1999). Selfdefense thus aligns well with the articulated goals of primary prevention in the public health model. Ironically, the misunderstanding of self-defense's role in sexual assault prevention and education often stems from the assumption that it does not produce population-level change but instead is too individualistic.

Even though it is perfectly reasonable to have an individual response, we, and others (Hollander 2009, 2013; McCaughey, 1997; McCaughey \& Cermele, 2014), have argued that self-defense has a population-level impact, changing gender ideologies, behaviors, and community norms "upstream." While some may believe that emphasizing self-defense is a neoliberal, individualistic response to the problem of campus sexual assault, we posit instead that training and engaging in self-defense could become a basis for female solidarity. This demands seeing men's violence against women as what Lamb (1999) refers to as "everyday violence", where such routine gendered hostilities demand a resistance rooted in what Lamb calls “everyday strength" (Lamb, 1999, p. 132). Celebrating women's strength hardly erases the reality of women's victimization, and, as Frazier and Joffe Falmagne (2014) argue, discussions of how women can prevent assault highlight the simultaneous positioning of women as both 
(C)2015 Martha McCaughey \& Jill Cermele

Forthcoming in Trauma, Violence, \& Abuse http://tva.sagepub.com

p. 35

"empowered and victimized" (p. 480). But as many scholars in the field of gender violence have noted (Lamb, 1999, Renzetti, 1999), the rather pervasive emphasis on women as victims, as an attempt to invoke sympathy for women, actually fails to challenge the gender hierarchy that perpetuates the everyday gendered hostilities women endure.

Self-defense as primary prevention can be less appealing to some people because they may prefer to associate men with a protector role and women with a damsel-in-distress role. Embracing self-defense simultaneously challenges the gender status quo in ways that may be discomfiting even to those who are adamantly against violence against women. Further, those who associate feminism with anti-individualist virtues may be opposed to teaching women to defend themselves, violently if necessary, because they associate feminism with antiindividualism and a critique of neo-liberalism. Ironically, it is the valorization of victims and the approach that offers them individual therapy and individual legal redress that de-politicizes sexual assault (Lamb, 1999, pp. 131-132) and therefore could be criticized as the individualist, de-politicized solutions to the problem.

Taking the CDC's four public health principles - health of the public, data-informed approaches, cultural competency, and prevention—-for sexual violence prevention, campus RPE programs have embraced bystander intervention training programs, but not self-defense training. The research on the efficacy of self-defense suggests that a truly data-informed approach would incorporate self-defense training explicitly at every level of campus RPE work. The recommendation to include self-defense training in RPE efforts is not a criticism of the new governmental mandates for strengthening RPE; it is a reasonable, data-driven interpretation of them. Indeed, only through the inclusion of self-defense training in college RPE programs can we avoid the hidden curriculum of current RPE programs and more effectively prevent sexual 
(C)2015 Martha McCaughey \& Jill Cermele

Forthcoming in Trauma, Violence, \& Abuse

http://tva.sagepub.com

p. 36

assault on campus. Our concluding section offers specific recommendations on the inclusion of self-defense training for those forming and implementing RPE policies and guidelines at federal, state, and local levels.

\section{Teaching Women How to Swim: Recommendations for Incorporating Self-Defense into RPE Efforts}

We have argued here that women's self-defense is a key protective factor that belongs in the primary prevention efforts of RPE programs on campuses and that, without it, we find a hidden curriculum that ultimately fuels the existing cultural perceptions of men's superiority over women and women's inability to thwart attacks. The new mandates must include, rather than ignore or actively exclude, self-defense training as an effective "upstream" method of sexual assault prevention. Women's ability and willingness to resist gendered violence and victimization can and should be incorporated into RPE efforts at all levels--messaging, data collection and sharing, trainings, assessment, funding, and general campus goals--in a way that acknowledges such resistance as part and parcel of our primary prevention efforts.

We should note that in recommending the inclusion of self-defense training we anticipate that some will object on cost grounds alone. We would respond that paying to provide selfdefense training could more than pay for itself, given the costs of handling sexual assault grievances, Title IX violations, RPE coordinators, and crisis counseling on campus. Some have suggested that the cost of higher education and the soaring number of university administrators is due to these increased government demands for accountability that involve "keeping every student safe and secure" (Kirk, 2014, para. 5). However, in light of the White House Task Force and the negative publicity so many schools are getting around the ways in which they address (or fail to address) sexual assault, significant resources are already being dedicated to this issue. 
(C)2015 Martha McCaughey \& Jill Cermele

Forthcoming in Trauma, Violence, \& Abuse http://tva.sagepub.com $\quad$ p. 37

Rather than arguing that self-defense training is an additional cost for universities, we might more accurately frame self-defense as a cost-saving measure. For example, Sinclair et al. (2013) reported that offering self-defense training to girls in Kenya cost approximately $\$ 1.75$ in United States dollars, compared to $\$ 85$ dollars spent on immediate medical care for a rape victim, and not taking into account any additional costs for the longer term medical or psychosocial care required thereafter. Given this, self-defense training, like so other primary prevention programs, may be less costly than paying for treatment, victim redress, and institutional legal fees in the aftermath of assault. Thus we outline some specific ways self-defense training could be folded into existing RPE efforts.

Messaging. All campus websites should include self-defense training options no more than two clicks away from their main page of sexual assault prevention and education information, just as those pages usually have information about where to go if someone has been a victim of an attack. Those same web links should encourage women not only to report a completed assault but to report sexual assaults they thwarted. Poster campaigns and other messages on campus - aimed at men as well as women — should include the possibility that women can resist the attack (not that they are responsible for resisting the attack). Resource links and referral lists should always include information about where someone can get empowering self-defense training.

Tertiary prevention including reporting, speak-outs, art-based activism, and role-playing scenarios about sexual assault could easily include women's self-defense successes, rather than only information about women victims and the importance of bystander intervention. Posters and social marketing have recently attempted to speak to different ethnic and racial groups, and 
(C)2015 Martha McCaughey \& Jill Cermele

Forthcoming in Trauma, Violence, \& Abuse

http://tva.sagepub.com

p. 38

language communities, but must begin to overcome not just racism or ethnocentrism but sexism

by speaking to women and men about women's strength, not simply men's strength.

In addition, the CDC's "Violence Prevention Success Stories" archives (Veto Violence,

Violence Education Tools Online, n.d.) could share information about self-defense strategies that worked to thwart attacks. Offering stories of self-defense that worked and featuring empowered women in social media and other imagery which can be linked to one's campus efforts or organization's identity would help RPE messages stop fetishizing victims and stop marginalizing those who resist. Such messaging strategies should also place the moral and legal blame for assault on the perpetrators, not the victims (whether or not they fought back). Messaging that includes, rather than excludes, women's ability to resist would avoid the hidden curriculum that women are vulnerable, easy targets.

Data Collection and Sharing. Colleges and universities need to keep, and share, data on women who successfully fought back. In accordance with Title IX, equal access to education should include access to the data on the effectiveness of rape resistance, and to training in effective verbal and physical self-protective strategies. Combining self-defense facts and statistics with the routine statistics on sexual assault would challenge the message that women's only options are to restrict their activities in an effort to avoid attack, hope for someone else to intervene, or go to the hospital for a rape kit. Many campuses already collect data on both attempted and completed assaults, but offer no information or explanation about attempted assaults. Of course, an assault that is attempted is an assault that was not completed, but unless that is articulated, attempted assaults are relegated to the category of "nothing really happened" (Cermele, 2010; Kelly \& Radford, 1996). Campus surveys can and should collect information about active resistance. Seeking more specific information about attempted assaults is likely to 
(C)2015 Martha McCaughey \& Jill Cermele

Forthcoming in Trauma, Violence, \& Abuse http://tva.sagepub.com

p. 39

yield data on assaults that were thwarted because of what women targeted for assault did to stop them, in addition to ways in which bystanders may have intervened. The CDC's "Violence Prevention Success Stories" archives would be a perfect place to share information from those who've received a CDC grant or who are CDC partners (Veto Violence, Violence Education Tools Online, n.d.).

Trainings. Self-defense information and instruction must be a part of the mandatory sexual assault prevention training for incoming students, faculty, and staff at colleges and universities, and all campus RPE learning objectives should include empowering self-defense training. Trainings that focus only on the definitions of terms, policies, and laws do a tremendous disservice to women who could thwart many possible attacks with the proper training and encouragement. Training materials and programs - including written training manuals and online training modules purchased through private vendors - must be developed and/or evaluated by people who understand the data on the effectiveness of self-defense in coordination with other experts. Further, all RPE leadership trainings should include selfdefense lessons for the leaders so that they have the opportunity to understand the physical transformation and the resultant transformation in consciousness that self-defense offers. Leadership trainings should also include self-defense training campaigns in the list of primary prevention activities. Providing self-defense training in addition to bystander intervention trainings, Title IX trainings, and trainings on victims' and first responders' reporting options would provide empowering information and skills to women about serving as their own bystanders, rather than only standing up for others, as well as challenge the belief that victim/bystander/perpetrator categories are discrete and non-overlapping. 
Assessment. All campus RPE assessment plans should include empowering self-defense training. SAFER's rubric should be modified to include the ability to assess self-defense as part of primary prevention efforts. Rubrics used for the evaluation of RPE programs should include whether or not a diverse group of women feel and become empowered, state their increased likelihood of intervening on their own behalves in resisting future acts of sexual assault, and report success thwarting sexual assaults. Similarly, RPE programs should be assessed for how frequently men report both an ability to thwart attacks and a greater appreciation for women's strengths and rights. The effectiveness of widespread training in self-defense for reducing the rape rate on campus should be studied alongside the effectiveness of widespread bystander intervention training for the same. Such multi-level assessment will contribute to the growing body of literature on the ways in which self-defense training promotes both individuals' physical and verbal personal safety skills and population-level shifts in beliefs about women, men, and sexual assault. Furthermore, in the CDC's collaboration with the Justice Department's Office on Violence Against Women and the Department of Education, their panel of experts should examine the research on self-defense when they work to identify promising practices to prevent sexual assault on campus.

Funding. Colleges and universities should spend more resources "upstream" by getting women trained in self-defense and forming partnerships with local high schools to offer girls such training. Reducing the number of completed attacks would reduce the legal fees, the number of paid counselors, and other crisis-management costs colleges and universities increasingly pay. Major government and nonprofit organizations_-including the CDC, VAWGO, and V-Day_-should explicitly list self-defense as a primary prevention strategy for which they approve funding, and self-defense programs should be among the RPE programs that 
(C)2015 Martha McCaughey \& Jill Cermele

Forthcoming in Trauma, Violence, \& Abuse http://tva.sagepub.com

the Justice Department's Office on Violence Against Women (OVW) grants money for and evaluates in its multi-year initiative on campus sexual assault.

Moreover, colleges and universities should position self-defense training as part of their RPE offerings, rather than simply referring to "interventions geared toward women". Vague references to women-oriented interventions will not solve the problem of the hidden curriculum, because such interventions have historically focused on teaching avoidance strategies and sexual assault statistics. "Interventions geared toward women" should explicitly include self-defense training and such interventions must be understood as primary prevention.

General Campus Goals. Self-defense training fulfills goals common to college campuses. For instance, the Core Commitments Initiative of the American Association of Colleges and Universities (AAC\&U) "focuses national attention on the importance of students exploring their ethical responsibilities to self and others" (AAC\&U, 2015). In collaboration with the Research Institute for Studies in Education (RISE) at Iowa State University, AAC\&U created a Personal and Social Responsibility Inventory (PSRI). The PSRI aims to enable campuses to assess the incorporation of personal and social responsibility into the curriculum and campus life programs. Self-defense training could be offered as one of the ways a campus cultivates the personal and social responsibility championed by the AAC\&U. Likewise, future research could measure self-defense training as a possible factor contributing to personal and social responsibility. Self-defense can be part of general campus wellness and health promotion efforts, for its benefits are not only in stopping attack and therefore preventing victimization but in the enabling of well-being and positive outcomes in the campus community. 
(C)2015 Martha McCaughey \& Jill Cermele

Forthcoming in Trauma, Violence, \& Abuse http://tva.sagepub.com p. 42

\section{References}

Abbey, A. (2002). Alcohol-related sexual assault: A common problem among college students. Journal of Studies on Alcohol and Drugs, 14, 118-128.

American Council on Education. (2014). New requirements imposed by the Violence Against Women Reauthorization Act. Retrieved from http://www.acenet.edu/newsroom/Documents/VAWA-Summary.pdf.

Banyard, V. L., Moynihan, M. M., \& Plante E. G. (2007). Sexual violence prevention through bystander education: An experimental evaluation. Journal of Community Psychology, 35(4), 463-481.

Banyard, V. L., Plante, E. G., \& Moynihan, M. M. (2004). Bystander education: Bringing a broader community perspective to sexual violence prevention. Journal of Community Psychology, 32(1), 61-79.

Barak, G., P. Leighton, \& A. Cotton. (2015). Class, race, gender, and crime: The social realities of justice in America. Lanham, MD: Rowman \& Littlefield.

Brecklin L. A., \& S. E. Ullman. (2005). Self-defense or assertiveness training and women's responses to sexual attacks. Journal of Interpersonal Violence, 20, 738-762.

Brecklin, L. A. (2008). Evaluation of self-defense training for women: A review. Aggression \& Violent Behavior, 13(1), 60-76. Breiding, M. J., Smith, S. G., Basile, K. C., Walters, M. L., Chen, J., \& Merrick, M. T. (2014). Prevalence and characteristics of sexual violence, stalking, and intimate partner violence victimization — National Intimate Partner and Sexual Violence Survey, United States, 2011. Morbidity and Mortality Weekly Report, 63(8), 1-18. Retrieved from http://www.cdc.gov/mmwr/pdf/ss/ss6308.pdf. 
(C)2015 Martha McCaughey \& Jill Cermele

Forthcoming in Trauma, Violence, \& Abuse http://tva.sagepub.com p. 43

Bringing in the Bystander (2014). Retrieved from http://cola.unh.edu/preventioninnovations/bringing-bystander $\% \mathrm{C} 2 \% \mathrm{AE}$.

Bystander Store Posters (2014). Retrieved from http://cola.unh.edu/preventioninnovations/bystander-store-posters

Campus Sexual Violence Elimination Act (2014). Jeanne Clery Act Information. Retrieved from http://www.cleryact.info/campus-save-act.html.

California Commission Against Sexual Assault (n.d.). Green Dot. Retrieved from http://www.calcasa.org/what-we-do/prevention/green-dot/

California Commission Against Sexual Assault (n.d.). My strength. Retrieved from http://www.calcasa.org/what-we-do/prevention/mystrength/

California Commission Against Sexual Assault (n.d.) Self-Defense. Retrieved from http://www.calcasa.org/what-we-do/prevention/self-defense/

Centers for Disease Control and Prevention. (2004). Sexual violence prevention: Beginning the dialogue. Atlanta, GA: Centers for Disease Control and Prevention. Retrieved from http://www.cdc.gov/violenceprevention/pdf/svprevention-a.pdf

Cermele, J. (2004). Teaching resistance to teach resistance: The use of self-defense in teaching undergraduate about gender violence. Feminist Teacher, 15(1), 1-15.

Cermele, J. (2010). Telling our stories: The importance of women's narratives of resistance. Violence Against Women, 16(10), 1162-1172

Clay-Warner, J. (2002). Avoiding rape: The effect of protective actions and situational factors on rape outcomes. Violence and Victims, 17(6), 691-705.

Cook-Craig, P., Millspaugh, P. H., Recktenwald, E.A., Kelly, N.C, Hegge, L. M., Coker, A.L., \& Pletcher, T.S. (2014). From Empower to Green Dot: Successful strategies and lessons 
(C)2015 Martha McCaughey \& Jill Cermele

Forthcoming in Trauma, Violence, \& Abuse http://tva.sagepub.com

learned in developing comprehensive sexual violence prevention programming. Violence Against Women, 20(10), 1162-1178.

DeGue, S. (2014). Preventing Sexual Violence on College Campuses: Lessons from Research and Practice. Prepared for the White House Task Force to Protect Students from Sexual Assault. Retrieved from Not Alone website:

$<$ https://www.notalone.gov/assets/evidence-based-strategies-for-the-prevention-of-svperpetration.pdf>. Date accessed Sept. 7, 2014.

Dix, G. E. (2010). Criminal law summaries on criminal law $\left(18^{\text {th }}\right.$ Ed). St. Paul, MN: Thomson/West.

Fisher, B. S., Cullen, F. T., \& Turner, M. G. (2000). The sexual victimization of college women. Washington, DC: National Institute of Justice, US Department of Justice.

Frazier, K. E., \& Joffe Falmagne, R. (2014). Empowered victims? Women's contradictory positions in the discourse of violence prevention. Violence Against Women, 24, 479-499.

Gidycz, C. A. \& Dardis, C. M. (2014). Feminist self-defense and resistance training for college students: A critical review and recommendations for the future. Trauma, Violence, \& Abuse, 15 (4), 322-333.

Glick, P., \& Fiske, S. T. (2001). An ambivalent alliance: Hostile and benevolent sexism as complementary justifications for gender inequality. American Psychologist, 56(2), 109118.

Gold, J. \& Villari, S. (Eds.) (2000). Just sex: Students rewrite the rules on sex, violence, equality and activism. Lanham, MD: Rowman and Littlefield. 
(C)2015 Martha McCaughey \& Jill Cermele

Forthcoming in Trauma, Violence, \& Abuse http://tva.sagepub.com p. 45

Good, J. (2011). Sexists observing sexism: Consequences for female targets of benevolent and hostile sexism. (Unpublished doctoral dissertation). Rutgers University: New Brunswick, NJ.

Good, J, \& Rudman, L. A. (2010). When female applicants meet sexist interviewers: The costs of being a target of benevolent sexism. Sex Roles, 62(7), 481-493.

Green Dot. (2014). Violence Intervention and Prevention Center. Retrieved from http://www.uky.edu/StudentAffairs/VIPCenter/learn_greendot.php

Heldman, C., \& D. Dirks. (2014). Blowing the whistle on campus rape. Ms. Winter/Spring, 3237.

Hollander, J. (2009). The roots of resistance to women's self-defense. Violence Against Women, $15(4), 574-594$.

Hollander, J. (2013). "I demand more of people": Accountability, interaction, and gender change. Gender and Society, 27(1), 5-29.

Hollander, J. (2014). Does self-defense training prevent violence against women? Violence Against Women, 20(3), 252-269.

Italiano, L. (2007, April 12). Attack of the killer lesbians. New York Post. Retrieved from http://nypost.com/2007/04/12/attack-of-the-killer-lesbians/.

Kates Jr, D. B., \& Engberg, N. J. (1982). Deadly force self-defense against rape. University of California Davis Law Review, 15, 873-906.

Kelly, L. \& Radford, J. (1996). “Nothing really happened”: The invalidation of women’s experiences of violence. In M. Hester, L. Kelly \& J. Radford (Eds.) Women, Violence, and Male Power (pp. 19-33). Philadelphia: Open University Press. 
(C)2015 Martha McCaughey \& Jill Cermele

Forthcoming in Trauma, Violence, \& Abuse http://tva.sagepub.com p. 46

Kirk, A. F. (2014, May 19). Think college costs too much? Thank the government. Chronicle of Higher Education. Retrieved from http://chronicle.com/article/Think-College-CostsToo-Much-/146641?cid=megamen. Date accessed August 25, 2014.

Krug, E., G., Dahlberg, L., L, Mercy, J. A., Zwi, A., B., \& Lozano, R. (Eds.) (2002). World Report on Violence and Health (Chapter 6, Sexual violence, pp. 147-182). Geneva, World Health Organization. Retrieved from $<$ http://www.who.int/violence_injury_prevention/violence/world_report/en/introduction. pdf $>$.

Lamb, S. (1999). Constructing the victim: Popular images and lasting labels. In S. Lamb (Ed.) New versions of victims: Feminists struggle with the concept (pp. 108-138). New York: NYU Press.

Lee, T. L., Fiske, S. T., \& Glick, P. (2010). Next gen ambivalent sexism: Converging correlates, causality in context, and converse causality, an introduction to the special issue [Special issue]. Sex Roles, 62(7-8), 395-404.

Martinez, J. (2007, April 19). Lesbian wolf pack guilty. Daily News. Retrieved from http://www.nydailynews.com/news/crime/lesbian-wolf-pack-guilty-article-1.209128.

McCaughey, M. (1997). Real knockouts: The physical feminism of women's self-defense. New York: New York University Press.

McCaughey, M. (2000). Kicking into consciousness through self-defense training: Getting physical in both theory and practice. In J. Gold \& S. Villari (Eds). Just sex: Students rewrite the rules on sex, violence, equality and activism (pp. 157-166). Lanham, MD: Rowman and Littlefield. 
(C)2015 Martha McCaughey \& Jill Cermele

Forthcoming in Trauma, Violence, \& Abuse http://tva.sagepub.com $\quad$ p. 47

McCaughey, M. (2013). Victim vaginas: The V-Day Campaign and the vagina as symbol of female vulnerability. Women's Studies, 42, 924-936.

McCaughey, M., \& Cermele, J. (2014). Guest editors' introduction. Violence Against Women, 20(3), 247-251.

Moynihan, M. M., Banyard, V. L., Arnold, J. S, Eckstein, R. P., \& Stapleton, J. G (2010). Engaging intercollegiate athletes in preventing and intervening in sexual and intimate partner violence. Journal of American College Health, 59(3), 197-204.

Moynihan, M. M., Banyard, V. L., Arnold, J. S, Eckstein, R. P., \& Stapleton, J. G (2011). Sisterhood may be powerful for reducing sexual and intimate partner violence: An evaluation of the Bringing in the Bystander in-person program with sorority members. Violence Against Women, 17(6), 703-719.

Not Alone (2014a). The First Report of the White House Task Force to Protect Students From Sexual Assault. U.S. Government. Retrieved from $<$ https://www.notalone.gov/assets/report.pdf $>$.

Not Alone: Together Against Sexual Assault. (2014). U.S. Government. Retrieved from $<$ https://www.notalone.gov/students/>.

Orchowski, L. M., Gidycz, C. A., \& Raffle, H. (2008). Evaluation of a sexual assault risk reduction and self-defense program: A prospective analysis of a revisited protocol. Psychology of Women Quarterly, 32(2), 204-218.

Ozer, E. M., \& Bandura, A. (1990). Mechanisms governing empowerment effects: A selfefficacy analysis. Journal of Personality and Social Psychology, 58(3), 472-486. 
(C)2015 Martha McCaughey \& Jill Cermele

Forthcoming in Trauma, Violence, \& Abuse http://tva.sagepub.com p. 48

Potter, S. J., \& Moynihan, M. M. (2011). Bringing in the Bystander in-person prevention program to a U. S. military installation: Results from a pilot study. Military Medicine, $176(8), 870-875$.

Preventing Pregnancies in Younger Teens. (2014). CDC Vital Signs. April. Retrieved from $<$ http://www.cdc.gov/vitalsigns/young-teen-pregnancy/index.html>.

Public Health Approach to Violence Prevention (2014). Center for Disease Control and Prevention, Injury Prevention \& Control: Division of Violence Prevention. Retrieved from http://www.cdc.gov/violenceprevention/overview/publichealthapproach.html.

Renzetti, C. (1999). The challenge to feminism posed by women's use of violence in intimate relationships. In S. Lamb (Ed.) New versions of victims: Feminists struggle with the concept (pp. 42-56). New York: NYU Press.

Rosenblum, G. D., \& Taska, L. S. (2014). Self-defense training as clinical intervention for survivors of trauma [Special issue]. Violence Against Women, 20(3), 293-308.

Rozee, P. D. \& Koss, M. P. (2001). Rape: A century of resistance. Psychology of Women Quarterly, 25(4), 295-311.

SAFER \& V-Day. (2013a). Making the grade? Findings from the campus accountability project on sexual assault policies. New York: SAFER (Students Active for Ending Rape). Retrieved from $<$ http://www.safercampus.org/blog/2013/10/safer-announces-findings-ofcampus-accountability-report/>. Accessed Sept. 29, 2014.

SAFER \& V-DAY. (2013b). V-Day and SAFER campus accountability project. Retrieved from $<$ http://www.vday.org/cap\#.VCl8XBb5zbp $>$.

Searles, P. and R. J. Berger. (1987). "The feminist self-defense movement: A case study." Gender and Society, 1:(1), 61-84. 
(C)2015 Martha McCaughey \& Jill Cermele

Forthcoming in Trauma, Violence, \& Abuse http://tva.sagepub.com p. 49

Senn, C. Y. (2011). An imperfect feminist journey: Reflections on the process to develop an effective sexual assault resistance programme for university women. Feminism and Psychology, 21(1), 121-137.

Senn, C. Y., Eliasziw, M., Barata, P. C., Thurston, W. E., Newby-Clark, I. R., Radtke, H. L., \& Hobden, K. L. (2015). Efficacy of a sexual assault resistance program for college women. New England Journal of Medicine, 372(24), 2326-2335.

Senn, C. Y., \& Hobden, K. L. (2015, March). Empowering women to resist sexual assault: What it does and doesn't do. Paper presented at the meeting of the Association for Women in Psychology, San Francisco, CA.

Sinclair, J., et al. (2013). "A Self-" ${ }^{\circ}$ Defense program reduces the incidence of sexual assault in Kenyan adolescent girls.” Journal of Adolescent Health, 53(3), 374-380.

Smith, M. D. (Ed). (2004). Encyclopedia of rape. Westport, CT: Greenwood.

Tark, J., \& Kleck, G. (2014). Resisting rape: The effects of victim self-protection on rape completion and injury [Special issue]. Violence Against Women, 20(3), 270-292.

Testa, M., \& Livingston, J. A. (2009). Alcohol consumption and women's vulnerability to sexual victimization: Can reducing women's drinking prevent rape? Substance Use and Misuse, 44(9-10), 1349-1376.

Thompson, M. E. (2014). Empowering self-defense training. Violence Against Women, 20(3), $343-350$.

Tjaden, P. \& Thoennes, N. (2006). Extent, nature and consequences of rape victimization: Findings from the national violence against women survey. Washington, DC: National Institute of Justice. 
(C)2015 Martha McCaughey \& Jill Cermele

Forthcoming in Trauma, Violence, \& Abuse http://tva.sagepub.com p. 50

U.S. Department of Education (2011, April 4). Dear Colleague Letter. Retrieved from http://www2.ed.gov/about/offices/list/ocr/letters/colleague-201104.html.

Ullman, S. E. (1997). Review and critique of empirical studies of rape avoidance. Criminal Justice and Behavior, 24, 177-204.

Ullman, S. E. (2007). A 10-year update on "Review and critique of empirical studies of rape avoidance." Criminal Justice and Behavior, 34(3), 411-429.

Ullman, S. E., \& Knight, R. A. (1993). The efficacy of women's resistance strategies in rape situations. Psychology of Women Quarterly, 17, 23-38.

Veto Violence, Principles of Prevention, Center for Disease Control (n.d.) Core courses, Principles of Prevention (POP). Retrieved from https://vetoviolence.cdc.gov/educationpop.html

Veto Violence, Violence Education Tools Online, Center for Disease Control (n.d.). Welcome to violence prevention success stories. Retrieved from http://vetoviolence.cdc.gov/success/searchresults.aspx? $\mathrm{cm}=0 \& \mathrm{iv}=0 \& \mathrm{sc}=0 \& \mathrm{sv}=-$ $1 \& \mathrm{nv}=0 \& \mathrm{yv}=0$

Zatz, M. S. (2000). "The convergence of race, ethnicity, gender, and class on court decision making: Looking toward the 21st century." Pp. 503-552 in Criminal Justice, 3. Washington, D.C.: U.S. Department of Justice Office of Justice Programs. 